\title{
Proposal and Validity of Global Intelligence Partnering Model for Corporate Strategy, "GIPM-CS"
}

\author{
Manabu Yamaji and Kakuro Amasaka \\ Aoyama Gakuin University, \\ 5-10-1 Fuchinobe Sagamihara Kanagawa, Japan \\ \{yamaji,kakuro_amasaka\}@ise.aoyama.ac.jp, \\ http://web.ise.aoyama.ac.jp/newjit/
}

\begin{abstract}
One of the requisites for winning corporate competitions today is success in the "global marketing" for quickly offering high-quality, latest model products in response to customer needs. For manufacturers to advance "manufacturing" that precisely meets the customers' preferences, it is vital that their affairs and management sections also share the global view and become a core of corporate management and strategy. More specifically, the key to success in "global production" lies in full functionalization of "partnering," in which forefront divisions of technology, production, and sales as well as the affairs and management sections collaborate in a cooperative strategic scheme to realize "global quality and optimal production." This study proposes Global Intelligence Partnering Model for Corporate Strategy, "GIPM-CS" mainly in connection with the administration. Further, the effectiveness of this model is verified at the successful companies.
\end{abstract}

\section{Keywords}

Affairs and Management sections, GIPM-CS, Global Partnering

\section{Introduction}

In recent years, in the context of quality management, the concept of "quality" has been expanded from "product quality" to "quality in the business process," and then even to "quality in corporate management" [1-3]. Against this background, in order to create products which respond to customer needs and, by extension, even customer wants, it is important to manage the realization of the mission of each division involved in the management of technology through "partnering $[2,3]$ " the management section, which organically links the technology, production and sales 
divisions and the affairs section, which activates members in all divisions to revitalize the organization.

Having said the above, this study strategically deploys the "next generation quality management technology, Science TQM [2, 4]," which has been proposed by the authors and verified as to its effectiveness. The authors then propose the Global Intelligence Partnering Model for Corporate Strategy, "GIPM-CS" which improves the intellectual productivity of the affairs and management sections. Then, the effectiveness of GIPM-CS will be verified by going over the application results observed at Toyota Motor Corporation.

\section{Management issue}

\subsection{Global Production Strategy}

The management values shared by so-called "winning companies" are shifting from emphasis on materials to human resources. The companies have amassed human resources, materials, and finances. It is easy to procure materials as well as finances. However, human resources take time to develop, and therefore, is not as easy as the foregoing to procure. The companies are endeavoring to grasp the information on human resources, take hold of the work, and formulate the vision in order to compete at a higher level.

It has been increasingly difficult to differentiate companies only in terms of "high product quality," "cost performance," and "superiority in the business process." It is imperative therefore to improve the value of human resources, but only a few companies have actually constructed a mechanism for improving human resources. Up until now, each department has acquired information on human resources from the personnel affairs division, and systems for offering such information have been insufficient. By improving the system for sharing information on human resources, similar to sharing information on materials and finances, the business assets of companies can be effectively utilized.

Moreover, the information of in-company systems has not been completely updated until the end of fiscal terms. Therefore, the accuracy of the information provided has been inferior, and the judgments regarding management tend to rely on personal experience or inspiration. In other words, information sharing has not been speedy enough. From now on, it is necessary to offer information with high precision based on the PDCA cycle so that decision-making on management matters will be based on facts. To that end, a system capable of analyzing all data, including human resources, from a variety of angles must be prepared. Under such a circumstance, there are many studies abroad for globalization $[5-7]$ and TQM $[8,9]$

\subsection{Issues of the Affairs and Management Sections}

Having said the above, in order to effectively utilize the role and function of each division, it is vital to recognize the issues related to the affairs and management sections, and to work on solving them. The authors find that the issues involving the 
affairs and management sections which need to be kept in mind when implementing strategic quality management are as follows:

1) The information is kept on a personal basis in many cases, not efficiently shared within the division.

2) They are lagging behind the other divisions, which are directly undertaking manufacturing operations, in the development of information technology (interdivision and intra-division information sharing)

3) Due to lack of communication with those outside the company.

4) They do not have systems for mid-term and long-term human resource development.

\section{Improvement in Intellectual Productivity of the Affairs and Management Sections}

It has been increasingly important for the affairs section to further advance the corporate management by grasping the environmental changes inside and outside the company in order to reinforce the internal and external management. For this reason, human resource development must be positioned at the core of management planning more emphatically than before so that the "reliability of company, organization, and human resources" can be enhanced. In the stage for utilizing (training) human resources, the function of improving intellectual productivity must be strengthened by partnering with the management section.

Likewise, the management section needs to function at the core of management technology and control. Therefore, it is deemed indispensable for them to reinforce the function of implementing JIT in the business flows of human resources, technology, and materials, through utilizing intellectual information as well as cooperating with the affairs section so that the onsite manufacturing divisions can be well managed internally.

The authors have verified the effectiveness of TIS (Total Intelligence Management System, Fig.1) for the management section, and TJS (Total Job Quality Management System, Fig.2) for the affairs section [10]. In order to activate the role and function of the affairs and management sections, in addition to practical application of the above core technologies, the authors believe that the role and function of the affairs and management sections can be integrally linked to business (high cycle-ization of the business process), as well as with the core technologies of onsite manufacturing divisions, such as TMS (Total Marketing System), TDS (Total Development System), and TPS (Total Production System) to implement strategic JIT.

In this connection, what is required of the affairs and management sections is to have the will and initiative to take responsibility in solving various management issues in cooperation with onsite manufacturing divisions. The authors think that the sections are "expected to play the role" of taking a proactive leadership role in putting together all the related divisions. 
(b)Information management

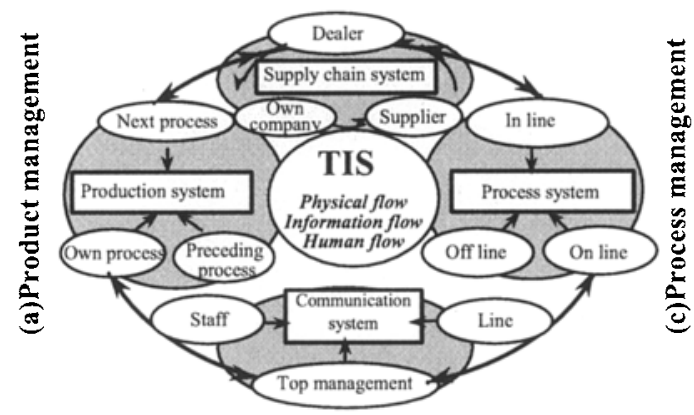

(d)Human management

Fig.1 Concept of TIS

(b)Global partnering

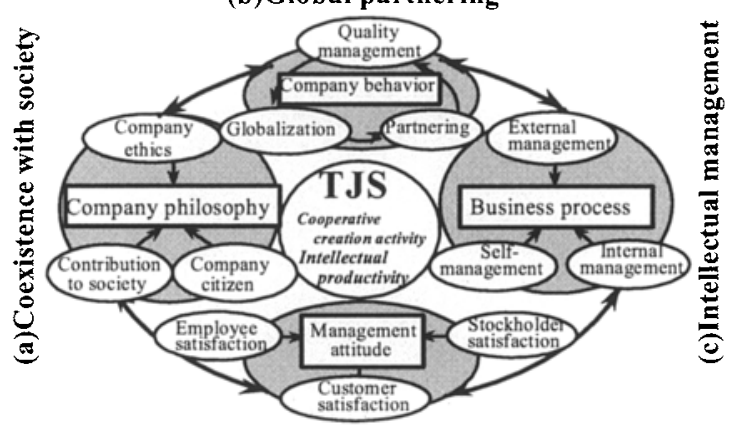

(d)Customer-in

Fig. 2 Concept of TJS

\section{Proposal of Global Intelligence Partnering Model for Corporate Strategy, "GIPM-CS"}

In recent years, Japanese companies have introduced the Western-style division of labor. Such a western labor division system is designed for easy replacement of labor forces and is achievement-oriented, it evaluates the degree of personal contribution to target achievement. Therefore, when a problem arises, it is dealt with not as a personal problem, but only within their responsibility range. Consequently, many activities and actions based on such a principle have been criticized by society. On the other hand, in the former Japanese system, problems were handled by all members across departments, which was a strong point of the Japanese way.

Based on the discussion in the previous chapter, the authors established the Global Intelligence Partnering Model for Corporate Strategy, "GIPM-CS" as shown in Fig. 3. The following are the functions of the affairs and management sections as corporate 
environment factors for succeeding in "global marketing," customer-first, 1) CS, ES, SS, for 2) high quality product and as a strategic factor to realize it, in order to 3) product reliability and corporation reliability, and success in 4) Intellectual productivity and human resource development. 5) Global production is realized by these. So the same quality and production at optimal locations are achieved. For that purpose, the highest priority was given to the "i) Intellectual information sharing" and "ii) Strategic Co-Creative Action" so that the "Strategic intelligence Application System" and "Business Process High Linkage System" can effectively function.

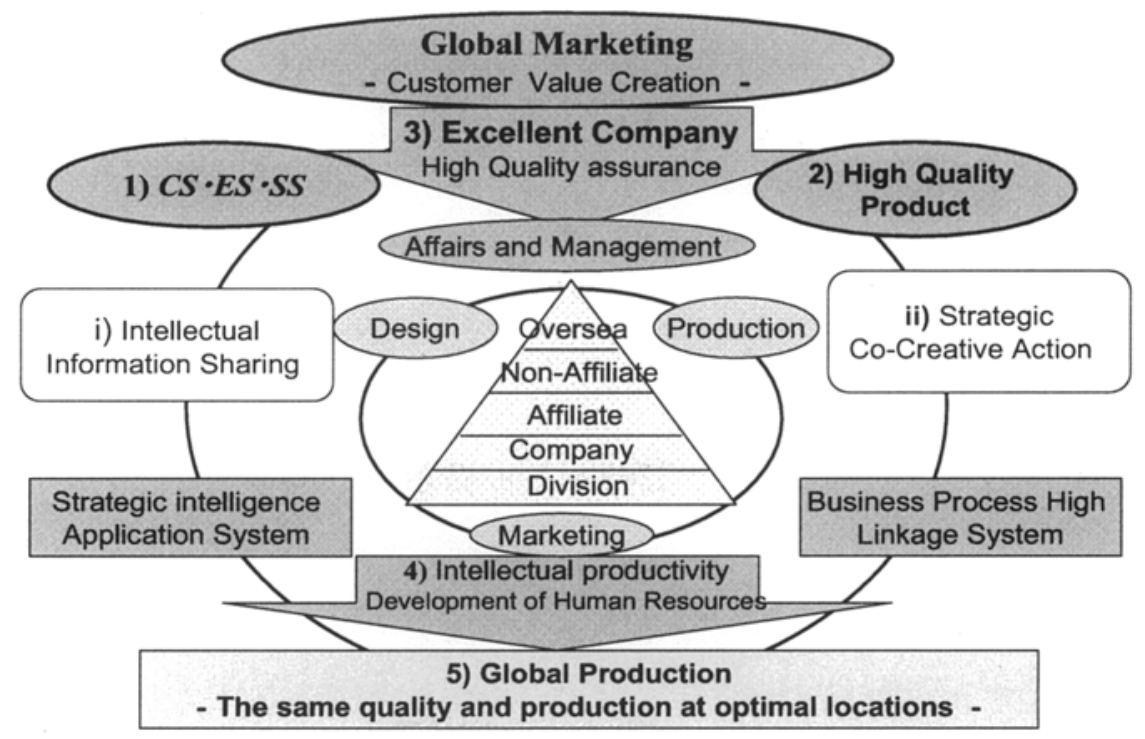

Fig. 3. GIPM-CS

When implementing a high cycle-ization of a business flow that consists of the setup of management policy, creation of a business plan, budget establishment, business deployment, optimal workforce distribution, task management, and evaluation, the relevant information needs to be shared among many departments and they need to also grasp the numerical values that show company-wide trends. In that way, upon confirming abnormal numerical indications, the problem can be identified and solved at an early stage. For example, if overtime labor cost shows an unusual figure, the project manager should find out the cause by checking which division, as well as which position or which process, is showing such a trend. In the personnel division, consideration needs to be given to possible deterioration of the work environment or lack of labor force, and in the sales division, care must be exercised to not delay delivery. Each division exchanges information with the other divisions to solve the problem as a whole company. The solutions shall be evaluated so that the information sharing of both problems and solutions can become a preventive measure and food for thought for the next plan.

Such a "partnership" among divisions, involves the creation of a system to visualize the information flow as well as its effective and 
practical application. To that end, a leader who links human resources is indispensable, and therefore, the cornerstone of corporate management is to foster leaders who have the understanding of the vision of management directors, a broad view of world trends, and communication skills to create a network of personnel inside the company. Simply put, the cultivation of an entrepreneurial mind or professional mind is what the authors are intending by proposing this "business model of intellectual productivity improvement for the affairs and management sections." In the following chapter, the effectiveness of the proposed "GIPM-CS" is verified through application cases at Toyota.

\section{Application}

\subsection{Intelligent Quality Control System "TPS- $Q A S$ " by Utilizing " $T$ - $Q C I S$ " and "T-ARIM"}

The application line of the TPS-QAS (-Quality Assurance System) [11] using Toyota's Quality Control Information System (T-QCIS) is the automated assembly line, which assembles a part that transmits engine-driven power to the tires. This software shows the necessary control characteristics hierarchically specified as Item, Detailed Items, and Extraction Conditions to improve operability and provide an expansion function.

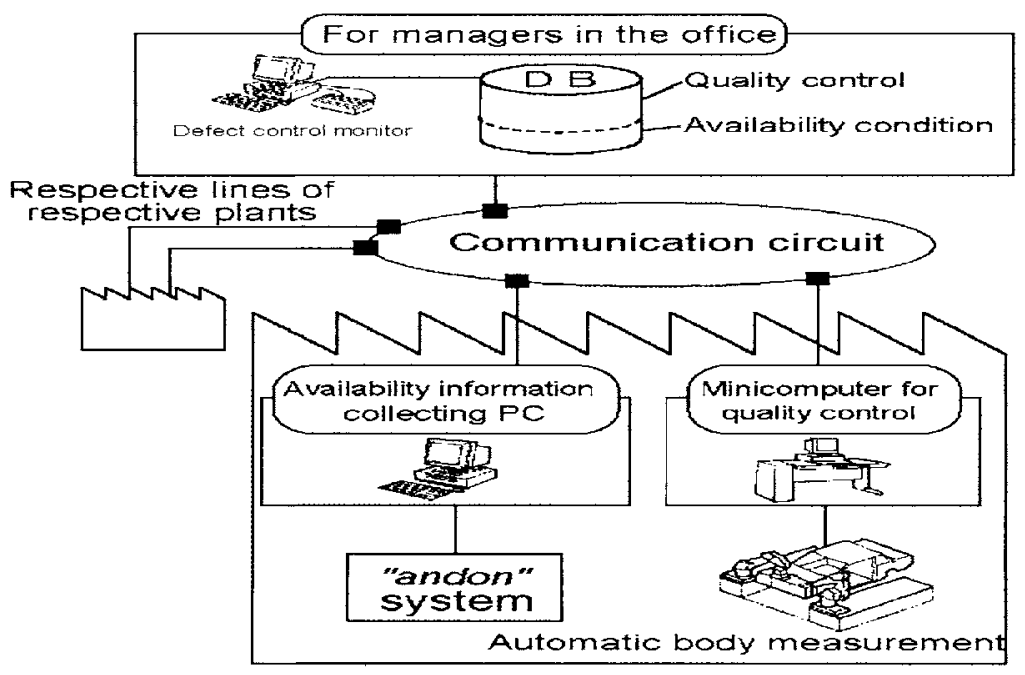

Fig. 4 Example of T-ARIM Hardware System 
As the support functions for making diagnosis of a process and taking necessary measures according to the findings obtained from the control chart, a scroll function and raw data indication function are newly added. These functions help improve the process by processing and indicating group data according to the purpose of analysis. Regarding the hierarchical factorial analysis, data is allocated after being stratified to trace the causal relation of the factors. Past know-how is utilized by developing the database of the history of improvement, and a warning of abnormal process is generated automatically by using IT to extract processes with and without abnormalities at random. The abnormal diagnosis function makes efficient operation possible. Regarding data link with other application software, real-time factorial analysis becomes possible using the SQC (Statistical Quality Control) analysis software. Introduction of $T$-QCIS has improved the $\mathrm{Cm}$ (machine capability) and $\mathrm{Cp}$ (process capability) of the overall vehicle production line as expected [12].

To ensure the effectiveness of this T-QCIS, the authors have constructed the "Toyota's High-Reliability Production System, Networking of Availability and Reliability Information Manufacturing System (T-ARIM)" [11] as shown in Fig.4, a network system constructed by the production engineering control division in coordination with the manufacturing division for the purpose of controlling production line operations and the reliability and maintainability of the lines. By implementing Inline-Online SQC [12], this system collects and processes Inline inprocess data Inline in real-time to control the process. It shares this intellectual information with related divisions, both domestic and/or overseas, to maintain or improve the processes scientifically using causal analysis, etc. The results are reflected in prompt improvement of the operating ratio of newly constructed lines. In practice, a system is then established for checking and following up on the quantitative improvement effects by analyzing changes in the failure mode before and after measures against failures, using Weibull chart analysis and other appropriate SQC tools.

\subsection{Improvement in Painting Quality of Chassis Parts of Automobiles \\ Cooperative Activities with Affiliated and Non-Affiliated Companies}

This case is simultaneous achievement of QCD for upgrading of automobile quality. Anti-corrosion has been an important issue for chassis parts of automobiles, and it has been a formidable challenge to resolve as it requires a comprehensive solution which encompasses materials, pre-treatment, paint, painting, and logistics. Conventionally, paint manufacturers and automobile manufacturers prepare paints on their own, and generally, the selection of paints was made after evaluation. This method, however, cannot keep abreast with the sophisticated, accelerating market needs. In order to simultaneously achieve quality, cost and delivery (QCD) across different industries and segmented organizations, it is necessary for paint manufacturers and automobile manufacturers to promote project activity in cooperation all the way from paint designing to building up paint quality.

As an example of this, Toyota carried out a project through formation of a task team with its affiliated company, Aisin Chemical Co., Ltd. as well as non-affiliated company Tokyo Paint Co., Ltd. Quality Assurance Div. collected quality data in the 
market. TQM Promotion Div. analyzes that data. The Fig. 5 shows the development process of paints used for the rear axel assay of automobiles in each improvement process for cost and quality. Up until now, styrene-altered alkyd resin paint has been used. To prevent the generation of initial rust, which resulted from applying an antifreezing agent mainly used in overseas markets, phenol-altered alkyd resin paint was adopted (Improvement 1), but as shown in the fig.5, the painting cost increased. The painting cost means not only the price of paints but includes the total cost involved, such as painting operation cost, energy consumption, facility maintenance and cleaning cost, inspection cost, etc. per vehicle.

Against this background, an extensive project was launched in which the everincreasing quality level required by the market is predicted and the target value is set in several steps for implementation in a planned manner. The first few years were spent improving the paint quality (Improvements 1 to 7 ) and after that, efforts were made in parallel to improve the painting facilities (Improvements 4 to 8 ). As a result, a type of paint with anticorrosive properties 10 times the conventional type was developed and the painting cost was reduced by more than $30 \%$, a considerable improvement [3].

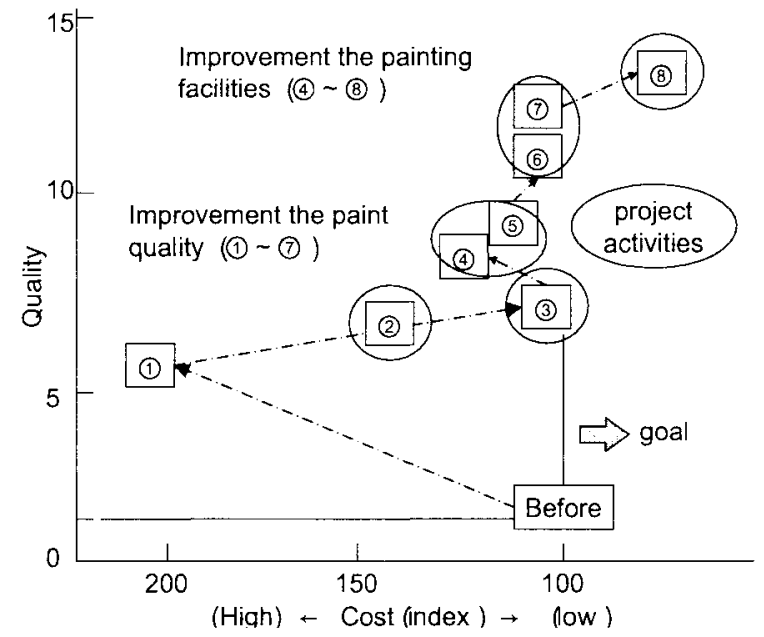

Fig. 5 Improvement process of the paint

\section{Conclusions}

The authors proposed the Global Intelligence Partnering Model for Corporate Strategy, "GIPM-CS" which improves the intellectual productivity of the affairs and management sections. The effectiveness of GIPM-CS was verified by going over the application results observed at Toyota Motor Corporation. 


\section{References}

1. Amasaka, K., New JIT, A New Management Technology Principle at Toyota, International Journal of Production Economics, Vol. 80, pp.135-144, 2002.

2. Amasaka, K., Development of "Science TQM", A New Principle of Quality Management: Effectiveness of Strategic Stratified Task Team at Toyota-, International Journal of Production Research, Vol.42, No.17, pp.3691-3706, 2003.

3. Amasaka, K., Applying New JIT--A Management Technology Strategy Model at Toyota - Strategic QCD Studies with Affiliated and Non-affiliated Suppliers, Proc. of the $2^{\text {nd }}$ World Conference on POM, Cancun, Mexico, pp.1-22, 2006 .

4. Amasaka, K., New Japan Model - Science TQM: Theory and Practice for Strategic Quality Management, Maruzen, 2007. (in Japanese)

5. Yamaji, M. and Amasaka, K., New Japan Quality Management Model, Hypercycle model "QA \& TQM Dual System", Proc. of the International Manufacturing Leaders Forum, Taipei, Taiwan, pp.1-6, 2006.

6. Lagrosen, S., Quality management in global firms, The TQM Magazine, Vol. 16, No. 6, pp. 396-402, 2004.

7. Ljungström, M., A model for starting up and implementing continuous improvements and work development in practice, The TQM Magazine, Vol. 17, No. 5, pp. 385-405, 2005.

8. Burke, R.J. et al., Effects of reengineering on the employee satisfaction-customer satisfaction relationship, The TQM Magazine, Vol. 17, No. 4, pp. 358-363, 2005

9. Evans J. R. and Lindsay W. M., The Management \& Control of Quality, SouthWestern, 1995.

10. Amasaka, K Advanced Science TQM, A New Japan Quality Management Model: Development of Global Production Strategy in Toyota, The $18^{\text {th }}$ International Conference on Production Research, Univ. of Salerno, Italy, pp. 1-6 (CD-ROM), 2006.

11. Amasaka K. and Sakai, H., TPS-QAS, new production quality management model: Key to New JIT, International Journal of Manufacturing Technology and Management, 2006. (decided to be published).

12. Amasaka, K. and Sakai, H., Availability and Reliability Information Administration System "ARIM-BL" by Methodology in "Inline-Online SQC", The International Journal of Reliability \& Safety Engineering, Vol.5, No.1, pp.55$63,1998$. 